\title{
1. Behavioral industrial organization: a synthesis of behavioral economics and industrial organization
}

\author{
Elizabeth Schroeder, Carol Horton Tremblay and \\ Victor J. Tremblay
}

Over the last several decades behavioral economists have made important contributions to the discipline of economics. Behavioral economics uses insights from psychology and evidence from neuroscience and experimental studies to enhance our understanding of economic decisionmaking (Angner and Loewenstein, 2007). It is complementary to traditional or neoclassical economic theory, as behavioral economists incorporate behavioral factors into traditional models when this improves our empirical predictions and policy prescriptions (Chetty, 2015, 1). The Handbook of Behavioral Industrial Organization consists of chapters that explain how the toolkit of behavioral economics contributes to our understanding of industrial organization. ${ }^{1}$ This is a vast undertaking for two reasons.

First, industrial organization (IO) is a broad field of study. IO investigates the behavior of firms, market structure, industry performance and government policies that are designed to improve social welfare. ${ }^{2}$ As Tirole $(1988,3)$ points out, the number of topics can be almost limitless given that the boundaries of IO are fuzzy. In his words: "IO certainly begins with the structure and behavior of firms .... But there is more to IO than business strategy. The other side of the coin is the outsider's ... assessment of market efficiency. Imperfectly competitive markets (that is, most real markets) are unlikely to maximize social welfare." As a result, Tirole goes on to say that government intervention may improve market performance "through the promotion of competition through antitrust action, as well as certain forms of regulation." Traditional IO models have been neoclassical in that all economic agents (that is, consumers, producers and government officials) are taken to be optimizers of clearly defined objective functions. In other words, the maintained hypothesis is that all agents are "rational".

The second reason why a synthesis of behavioral economics and industrial organization is challenging is that there are many possible 


\section{Handbook of behavioral industrial organization}

behavioral biases that can arise in an IO setting. Examples include framing effects, cognitive dissonance, individual and social identity issues, loss aversion, motivated reasoning, myopia, overconfidence, salience, status quo bias, and time inconsistency. ${ }^{3}$ Coupling the many possible behavioral biases with countless IO issues leads to an almost limitless number of behavioral IO topics, as described in "Ellison's Matrix of Topics". According to Ellison (2006, 28):

Think of the set of behavioral biases as the column headings, and put all of the standard models in IO as the row headings: how will a monopolist price, how will a monopolist selling durable goods price, how will a monopolist price discriminate, how will oligopolists selling differentiated goods set prices, how will some action be distorted to deter or accommodate entry, etc. It takes little knowledge or imagination to come up with literally thousands of paper topics: Tirole's (1988) text has hundreds of IO models, each of which could be combined with dozens of behavioral-bias models.

A behavioral bias includes any human quality that causes people to behave suboptimally. As a result, behavioral miscalculations have been closely linked with the concept of "rationality". Agents with behavioral imperfections are sometimes said to be irrational (Akerlof and Dickens, 1982). ${ }^{4}$ This characterization can be confusing, however, because the concept of irrationality is not always clearly defined and is used to mean different things in the social science literature. ${ }^{5}$

Extreme neoclassical IO models may give poor predictions and policy prescriptions because they assume that all economic agents are rational. The simplest neoclassical models assume "perfect" rationality. ${ }^{6}$ Agents who are perfectly rational have unlimited reasoning ability, always pursue what is in their own best interest, and have complete information. They can never make a mistake because they know their preferences and have all of the information and reasoning capability needed to reach an optimal decision, however narrowly defined. Theorists have used this extreme assumption as a reductionist device to simplify the analysis and enable them to produce tractable models. ${ }^{7}$ When taken too far, however, the perfect rationality assumption can produce overly simplistic models that generate unreliable predictions (Arrow, 1986).

Classical economists ${ }^{8}$ certainly understood that the reasoning of real people is frequently imperfect. ${ }^{9}$ Nevertheless, the development of mathematical models that are based on flawed economic agents is relatively new. In order to avoid oversimplification and make more accurate predictions, behavioral IO models assume that economic agents suffer from the limitations of real people. They have complex (non-standard) preferences, limited cognitive ability, and inadequate information. Given 
that these traits can cause people to behave predictably but suboptimally, especially in complex economic environments, such agents are said to be "imperfectly" rational, "quasi" rational (Russell and Thaler, 1985), "limitedly" rational (Rabin, 2013), or "predictably irrational" (Akerlof and Dickens, 1982; Ariely, 2008).

A common type of imperfect rationality that is used in behavioral IO is "bounded rationality" (Simon, 1955). ${ }^{10}$ Agents who are boundedly rational have limited information and cognitive abilities, making it too costly for them to behave in a fully optimal way. In the face of these limitations, they use satisficing behavior - they choose an action that is satisfactory, or good enough, a behavioral strategy that need not lead to a fully optimal outcome.

The concept of satisficing behavior as it relates to imperfect rationality can be understood by contrasting "exact-optimization" with " $\varepsilon$ optimization" behavior (Dixon, 1992; Stahl, 2014). To illustrate, consider an agent who wishes to choose action $s$ that maximizes value function $U(s)$, such that $U$ reaches a unique (exact) maximum at $s^{*}$. For whatever reason, an agent who is boundedly rational has difficulty identifying $s^{*}$, and instead uses satisficing behavior. With satisficing behavior, the agent chooses action $s$, such that $U\left(s^{\varepsilon}\right) \geq U\left(s^{*}\right)-\varepsilon$ and $\varepsilon>0$. The choice of $s^{\varepsilon}$ is viewed as good enough given the cost of reducing $\varepsilon$. For a perfectly rational agent, $\varepsilon$ equals zero because the cost of reducing $\varepsilon$ is sufficiently low; whereas boundedly rational agents suffer from informational and cognitive limitations that make it prohibitively costly for them to reduce $\varepsilon$ to zero.

Although Simon described bounded rationality in terms of satisficing behavior, recent IO scholars think of it more broadly. For example, Ellison (2006) lists three ways in which the concept of bounded rationality has been used in behavioral IO - when making a decision, agents use: (1) a satisficing approach; (2) a rule-of-thumb (heuristic); (3) an approach that is influenced by one or more of the behavioral biases that are identified in the experimental economics and psychology literature. This broader perspective is evident in Spiegler's (2011) book on behavioral IO. Although it is titled Bounded Rationality and Industrial Organization, its goal is to develop IO models that are based on consumers who simply fall short of perfect rationality. In some cases consumers fail to reach a first-best solution because they use a satisficing strategy; in other cases they fail to optimize because they have complex preferences or are systematically biased due to such characteristics as overconfidence or time inconsistency. 


\section{Handbook of behavioral industrial organization}

The evidence shows that these behavioral weaknesses can afflict all relevant economic agents: consumers, producers and government bureaucrats. The earliest work in the behavioral IO tradition began with Pigou and Robertson (1924) who argued that real firms are unlikely to optimize. This was confirmed by Hall and Hitch (1939), who found that large corporations do not appear to behave as simple profit maximizers. Subsequent supporting evidence led to various behavioral theories of the firm. ${ }^{11}$ Recent extensions include the work by Malmendier and Tate (2008; 2011), who demonstrate that the personality of a company's chief executive officer (CEO) affects firm behavior and earnings. For example, they found that an overconfident $\mathrm{CEO}$ is more likely to undertake a merger that lowers the value of the firm and that a CEO with military experience is more likely to pursue an aggressive investment strategy.

There is considerably less work on the behavioral biases of government agents. Early studies of economic regulation focused on the motives of regulators. ${ }^{12}$ For example, the public interest theory states that regulations "should be" designed to promote the "common good". Nevertheless, a growing body of evidence confirmed that economic regulation frequently benefits special interest groups at the expense of society as a whole. This evidence motivated Stigler's (1971) theory of regulation, which maintains that regulators are more interested in enhancing their political power (or narrow self-interest) than in promoting the common good. Research is just beginning on the effect that psychological biases of regulators may have on the behavior of regulatory agencies (Cooper and Kovacic, 2012; Gubler, 2014). This appears to be a fruitful area of future research.

Much of the recent work in behavioral IO has focused on behavioral issues on the consumer side of the market. ${ }^{13}$ In this line of research, regulatory constraints on the firm are taken as given, and firms are assumed to be profit maximizers. Three reasons typically are used to justify the profit maximization assumption: (1) firms can hire expert consultants; (2) firms can focus on a limited number of markets; and (3) competition will cause firms to fail if they fall short of profit maximization. This is in contrast to the typical consumer who makes purchases in many markets, cannot afford to hire a purchasing expert, and may be more insulated from the consequences of financial failure (due to the financial assistance of friends, relatives and government programs). Thus, consumers are more likely to make errors and exhibit behavioral weaknesses. The main goal in this branch of behavioral IO has been to understand how firms exploit consumer weaknesses in order to convert consumer surplus into producer surplus. An excellent example is 
the article by Grubb (2009), which shows how cell phone companies have used three-part tariff contracts to exploit overconfident consumers.

Although many of the chapters in the Handbook of Behavioral Industrial Organization focus on consumer behavioral weaknesses, several chapters consider behavioral firms. Just and Cao (Chapter 6) show how overconfident managers cause firms to produce more output and have a higher probability of survival than profit maximizing firms. Waldman (Chapter 7) discusses how boundedly rational managers affect firm behavior. Butler (Chapter 9) shows how firms may benefit from creating a coherent social identity for the corporation. Finally, Coates and Humphreys (Chapter 12) discuss how boundedly rational owners/ managers affect outcomes in the sports industry.

More generally, the remaining chapters in the Handbook of Behavioral Industrial Organization are divided into two parts. The next, Part II, includes chapters that address a broad range of behavioral issues that are relevant to IO. Part III includes chapters that focus on behavioral concepts that pertain to particular industries and antitrust policy. The chapters on behavioral antitrust are last, because one can gain a better understanding of policy questions only when the behavioral principles that are discussed in the preceding chapters are understood. A brief summary of each chapter is provided below.

Part II of the book examines industrial organization models that emerge when economic agents have non-standard preferences. In Chapter 2 Azar and Mazooz survey the literature on relative thinking and its implications for IO. Relative thinking is a phenomenon in which consumers make choices based on relative prices, even in situations where only absolute price differences are relevant. A substantial body of experimental literature demonstrates, for example, that many people are willing to spend more time and exert more effort to save a given amount of money if the savings represents a greater percentage of the price of the item they are purchasing. According to utility maximization theory, however, the consumer should only compare the amount saved to the cost of obtaining the discount. The authors explore the potential psychological reasons for relative thinking, as well as many implications for IO. In particular, firms can take advantage of consumers' non-optimal decisionmaking when forming pricing strategies. An extension of this literature addresses differentiated goods; here, consumers must correctly value how much an improvement in quality is worth to them. These issues are important for both firms that maximize profits and policymakers who seek to educate and protect consumers.

There are many markets where firms hide information from consumers about prices and product characteristics. For example, banks frequently 
advertise interest rates on their accounts but conceal (that is, shroud) information on ATM usage fees and minimum balance requirements. In Chapter 3 Gabaix and Laibson show that such shrouding may exist in markets with naive and sophisticated consumers. While sophisticated consumers are not fooled, firms are able to exploit naive consumers with shrouded high-priced add-ons. Unlike the traditional arguments of Alchian (1950), Friedman (1953), and Arrow (1982), Gabaix and Laibson show that competition need not drive information shrouding out of the market. ${ }^{14}$

In Chapter 4 Herweg, Müller and Weinschenk model how profit maximizing firms will exploit consumers who suffer from salient thinking. A salient thinker puts excessive weight on a product characteristic that stands out. Their model shows how firms can manipulate consumer decisions by changing the size of their choice set. For example, consider a monopolist that sells two competing brands: brand 1 is of high quality and brand 2 is of low quality. Profit margins are higher on the highquality good, but most consumers prefer the low-quality good, ceteris paribus. Herweg, Müller and Weinschenk show that a firm can manipulate consumer demand by adding a third brand that is of higher quality than brand 1. Research in behavioral marketing shows that some consumers are more likely to buy intermediate (that is, salient) rather than extreme brands. Thus, the third brand is called a decoy. The addition of the decoy repositions brand 1 , making it the average brand and more attractive to consumers who suffer from this form of salience.

In Chapter 5 Stone and Wood show how three classic issues in psychology affect consumer choices and firm behavior. These are: (1) cognitive dissonance, the distress one feels when actions are inconsistent with beliefs; (2) motivated reasoning or reasoning that is motivated by some self-interest (Kunda, 1990); (3) confirmation bias, an inclination to seek information that conforms to one's pre-established beliefs. Stone and Wood document how little these concepts have been used by industrial organization economists. This is an important deficiency, because they show how firms can exploit consumers who exhibit these cognitive characteristics by distorting their tastes and changing their perceptions about product quality.

Managers of firms as well as consumers can suffer from overconfidence. In Chapter 6 Just and Cao investigate how firm overconfidence affects market outcomes. A firm's overconfidence has two dimensions: (1) overestimation of its average payoff; and (2) underestimation of the variance of its payoff. Just and Cao focus on the latter. In their model, firms that underestimate risk are likely to produce more output than profit-maximizing firms. In addition, competition may actually encourage 
overconfident behavior rather than drive it out of the market. The Just and Cao model predicts that firms that underestimate risk may be more likely to survive; competition does not guarantee profit maximization.

In Chapter 7 Waldman discusses how status quo bias affects imperfectly competitive markets. When people are reluctant to change their behavior, they make decisions based on inertia and are said to suffer from status quo bias. Waldman shows how boundedly rational managers are likely to deviate from profit-maximizing behavior because they are unwilling to break from what has been done in the past. Waldman also shows that consumer prices tend to be higher in markets with network effects, because of high consumer switching costs. Finally, he shows how status quo bias contributed to the financial crisis of the Great Recession.

In Chapter 8 Lukinova, Wilson and Myagkov conduct a series of experiments on the classic prisoners' dilemma. Their work challenges the prediction that defecting is always the dominant strategy for utilitymaximizing players in a one-shot game. The authors explore the domain of sociality by allowing participants to bid for the chance to play the game. They find that players who value being part of the game more highly are also more likely to cooperate, supporting the idea that more social individuals might derive utility from cooperation, as well as from the monetary payoff of the game. Prisoners' dilemma-type interactions are common in cartel behavior, and thus it is important for policymakers to understand how social interactions can reduce the incentive to defect.

In Chapter 9 Butler provides an overview of social identity theory and how it can affect firm efficiency. A person's social identity is defined by the set of personal characteristics that are shared by a social group. Association with a group can shape one's preferences and beliefs about one's deep preferences and values. Early work on social identity was used to understand discrimination - do social categories cultivate a preference for prejudice or does intergroup competition for resources cause discrimination across groups? Butler traces the development of the "economics of identity" and two prominent models, one preferencebased and the other beliefs-based. He shows how the notion of identity can help us to understand the classic IO question that was raised by Coase (1937) - why do firms exist? Additionally, creation of a social identity within a firm can generate a synergy that promotes an efficient corporate environment.

The chapters in Part III concentrate on behavioral issues as they apply to particular industries and antitrust policy. In Chapter 10 Eisenhuth, Murphy and Neuhierl investigate a classic question in gambling: why would risk averse individuals engage in casino gambling when the expected payoff is negative? Although this behavior cannot be explained 
with the standard expected utility framework, they show how it can be rationalized if agents have stake-dependent utility functions. With stake dependence, expected utility falls with risk but increases with the size of the wager. Placing a larger wager is of value, in and of itself. They endogenize stake-dependent preferences and allow gamblers to have different degrees of optimism about winning. Their framework explains a number of other phenomena in gambling, including why casinos offer a variety of games and why gamblers exhibit dynamically inconsistent behavior.

In Chapter 11 Berkowitz, Depken and Gandar use slot machine data from Florida casinos to test the law of one price. This law states that firms will charge consumers the same price when products are homogeneous and consumers are well informed. Berkowitz, Depken and Gandar find that the data are inconsistent with this law. Not only is there persistent price dispersion, but it has actually increased over time. Contributions from behavioral economics help explain this anomaly. First, gamblers are likely to be boundedly rational, as casinos make it difficult for them to identify expected payouts. Second, some gamblers suffer from behavioral biases. In some cases, gamblers believe that the probability of winning is higher if a machine has paid out several times in the recent past; in other cases gamblers believe that the probability of winning is higher if a machine has not paid out in a long time. Gamblers who are imperfectly informed or suffer from these behavioral biases may fail to identify and use low-price slot machines and eliminate price dispersion.

In Chapter 12 Coates and Humphreys survey the literature on behavioral economics and sports. Sports economics provides a rich environment to test behavioral hypotheses, as extensive data exist on both the firm-level decisions of teams and the choices of individual consumers. For example, coaches and managers can make irrational decisions due to undervaluation or overvaluation of player inputs or failure to disregard sunk costs; demand for tickets may depend on the reference-dependent preferences or loss aversion of fans; and individuals' decisions to exercise may suffer from time-inconsistent preferences. Other topics include the effect of behavioral biases in refereeing and the hot hand, in addition to various sports-industry regulations.

In Chapter 13 Carol Tremblay reviews a number of neuroeconomic studies on classic topics in industrial economics: advertising, brand names and pricing. What can brain activity tell us about the effects of these marketing strategies on consumer utility and choice? Carol Tremblay reports on neuroscience experiments, mainly using functional magnetic resonance imaging (fMRI), that address this question. The 
industries covered in the chapter include: cola, beer, coffee, wine, artwork, music, magazines, handbags, televisions, sunscreen, and cigarettes. Tremblay points out that researchers have identified a particular part of the brain associated with value (or utility) and that brain activity is now being used to predict choice, even at the population level.

The last two chapters in the Handbook of Behavioral Industrial Organization demonstrate how behavioral issues affect antitrust policy. In Chapter 14 Chowdhury and Wandschneider perform an experiment regarding the deterrence of cartel activity. They find that cartel activity falls with an increase in the expected punishment (that is, the severity of punishment and the probability of apprehension). Further, they find support for the "Beckerian Proposition" that detection rates and fines are substitutes. This result is untrue, however, when the experiment includes a cartel "leniency program" in which a reduced fine is offered to a firm that defects and provides antitrust authorities with evidence of a cartel. In this case, Chowdhury and Wandschneider find that a given level of deterrence can be reached more efficiently with high fines and low detection rates. This is a useful result when determining an optimal antitrust enforcement policy - fewer resources are needed to reach a given level of deterrence for a policy that includes a leniency program.

Martin's Chapter 15 completes the book, as it demonstrates how insights from behavioral IO are shaping antitrust policy more broadly. Martin reviews and contrasts theories of rationality and bounded rationality, and explores the implications of boundedly rational behavior by firms on our understanding of strategic anticompetitive behavior. He analyzes, in particular, predation, collusion and entry decisions in light of evidence of bounded rationality, and uses these insights to assess current antitrust rules and draw implications for antitrust policy.

These chapters highlight many of the important issues in behavioral IO and provide a platform for future research.

\section{NOTES}

1. Although the goal of the Handbook of Behavioral Industrial Organization is to show how behavioral economics contributes to the field of industrial organization, we do not mean to ignore the many successes of neoclassical economics. As Rabin (2013), a leading behavioral economist, points out, there are many contexts in which behavioral models fail to improve economic predictions over neoclassical models. For reviews of behavioral economics, both pro and con, see Camerer and Loewenstein (2004), Camerer (2008), Gul and Pesendorfer (2008), Harstad and Selten (2013) and Thaler (2016). 


\section{Handbook of behavioral industrial organization}

2. For examples of alternative definitions of industrial organization over time, see Scherer (1970), Greer (1980), Tirole (1988), Carlton and Perloff (2005), Martin (2010), Tremblay and Tremblay (2012) and Waldman and Jensen (2016).

3. Readers who are unfamiliar with these behavioral issues can find more about them from Camerer and Lowenstein (2004), Camerer (2008), Tremblay and Tremblay (2012), Bernheim and Whinston (2014) and Epley and Gilovich (2016).

4. The prediction of an economic model critically depends upon the assumption of rationality or the reasoning ability of economic agents. On this issue Samuelson $(1997,3)$ states, "The richness of the [economic] problem grows out of our having no a priori notion of what it means to be rational, substituting instead a mixture of intuition, analogy, and ideology. The resulting models have a solid claim to being philosophy and art as well as science."

5. For a review of the literature on economic irrationality, see Eisenhuth and Tremblay (2017). One example is Becker (1962), who defines irrational behavior as random deviations from behavior that would derive from perfect rationality. Consumers choose randomly from their affordable set of consumption possibilities, and firms choose a level of production randomly from their technologically feasible set. Becker showed that markets may behave rationally, even though consumers and producers are irrational in this way. This is consistent with the experimental evidence that is summarized by Smith (1991).

6. Stahl (2014) identifies this extreme case as perfect rationality, but it is sometimes called "full rationality" (Smith, 1991; Rabin, 2013), and "hyper-rationality" (Thaler, 2000). For further discussion, see Thaler (2000) and Eisenhuth and Tremblay (2017). Because a rational player's best course of action depends upon the extent to which other players are rational, the concept of rationality is even more complex in a game theoretic setting (Camerer and Ho, 2015).

7. This viewpoint is shared by many theorists, including Einstein who said that "theories should be as simple as possible, but not simpler." In economics, Stigler $(1968,319)$ said that "the role of description is to particularize, while the role of theory is to generalize - to disregard an infinite number of differences and capture the important common element in different phenomena."

8. According to Oser and Blanchfield (1975), the classical school began in the late 18th century and ended with the development of marginalism or neoclassical theory in the late 19 th century.

9. For example, Adam Smith (1981 [1759]), the founder of modern economics, assumed multidimensional human beings who struggle with the opposing forces of passion and reason. In psychology today, these are considered modes of thinking and deciding. Kahneman $(2003,1450)$ argues that they "correspond roughly to the everyday concepts of reasoning and intuition." Thus, given that agents are psychologically realistic in Smith's analysis, he is considered an early behavioral economist (Ashraf et al., 2005). For further discussion, see Martin (this volume) and Coase (1976).

10. For a review of the industrial organization literature that uses the bounded rationality assumption, see Ellison (2006), Spiegler (2011), Eliaz and Spiegler (2015) and Grubb (2015a; 2015b).

11. For additional discussion, see Scherer (1970, chapters 2 and 6), Greer (1980, chapters 10 and 11) and Armstrong and Huck (2010).

12. For a review of the literature, see Viscusi et al. (2005).

13. For further discussion of this approach to behavioral IO, see Armstrong (2015), Bailey (2015), Eliaz and Spiegler (2015), Grubb (2015a; 2015b), Grubb and Tremblay (2015) and Heidhues and Köszegi (2015).

14. This is consistent with the work of Russell and Thaler (1985), who show that competition need not drive irrational behavior out of the market. Fehr and Tyran 
(2005) show how this conclusion depends on whether choice variables are strategic complements or substitutes. With strategic complements, a small number of irrational agents can cause market outcomes to deviate from the predictions of rational models. With strategic substitutes, only a small number of rational agents is required for the market to conform to the predictions of rational models.

\section{REFERENCES}

Akerlof, George A. and William T. Dickens (1982), "The Economic Consequences of Cognitive Dissonance", American Economic Review, 72 (3), June, 307-19.

Alchian, Armen A. (1950), "Uncertainty, Evolution, and Economic Theory", Journal of Political Economy, 58 (3), June, 211-21.

Angner, Erik and George Loewenstein (2007), "Behavioral Economics", in Uskali Mäki, editor, Philosophy of Economics, Amsterdam: Elsevier.

Ariely, Dan (2008), Predictably Irrational, London: HarperCollins.

Armstrong, Mark (2015), "Search and Ripoff Externalities", Review of Industrial Organization, 47 (3), November, 273-302.

Armstrong, Mark and Steffen Huck (2010), "Behavioral Economics as Applied to Firms: A Primer", Competition and Policy International, 6 (1), 3-45.

Arrow, Kenneth J. (1982), "Risk Perception in Psychology and Economics", Economic Inquiry, 20, 1-8.

Arrow, Kenneth J. (1986), "Rationality of Self and Others in an Economic System", Journal of Business, 59 (4), October, S385-S399.

Ashraf, Nava, Colin F. Camerer and George Loewenstein (2005), "Adam Smith, Behavioral Economist", Journal of Economic Perspectives, 19 (3), Summer, 131-45.

Bailey, Elizabeth M. (2015), "Behavioral Economics and U.S. Antitrust Policy", Review of Industrial Organization, 47 (3), November, 355-66.

Becker, Gary (1962), "Irrational Behavior and Economic Theory", Journal of Political Economy, 70 (1), February, 1-13.

Bernheim, B. Douglas and Michael D. Whinston (2014), Microeconomics, New York: McGraw-Hill Irwin.

Camerer, Colin (2008), "The Case of Mindful Economics", in Andrew Caplin and Andrew Schotter, editors, The Foundations of Positive and Normative Economics: A Handbook, Princeton: Princeton University Press, 43-69.

Camerer, Colin and Teck-Hua Ho (2015), "Behavioral Game Theory Experiments and Modeling", in H. Peyton Young and Shmuel Zamir, editors, Handbook of Game Theory, Volume 4, Amsterdam: North Holland, 517-74.

Camerer, Colin F. and George Loewenstein (2004), "Behavioral Economics: Past, Present, Future", in Colin F. Camerer, George Loewenstein and Matthew Rabin, editors, Advances in Behavioral Economics, Princeton: Princeton University Press, 3-52.

Carlton, Dennis W. and Jeffrey M. Perloff (2005), Modern Industrial Organization, Boston: Pearson Addison Wesley.

Chetty, Raj (2015), "Behavioral Economics and Public Policy: A Pragmatic Perspective", American Economic Review, 105 (5), May, 1-33.

Coase, Ronald H. (1937), "The Nature of the Firm", Economica, 4 (16), November, 386-405.

Coase, Ronald H. (1976), "Adam Smith's View of Man”, Journal of Law and Economics, 19 (3), October, 529-46.

Cooper, James C. and William Kovacic (2012), "Behavioral Economics: Implications for Regulatory Behavior", Journal of Regulatory Economics, 41 (1), February, 41-58. 


\section{Handbook of behavioral industrial organization}

Dixon, Huw (1992), "Some Thoughts on Economic Theory and Artificial Intelligence", in S. Moss and J. Rae, editors, Artificial Intelligence and Economic Analysis: Prospects and Problems, Cheltenham, UK and Northampton, MA, USA: Edward Elgar Publishing, 131-54.

Eisenhuth, Roland and Victor J. Tremblay (2017), "Reasoning Rationally", working paper, Department of Economics, Oregon State University, January.

Eliaz, Kfir and Ran Spiegler (2015), 'Beyond 'Ellison's Matrix': New Directions in Behavioral Industrial Organization", Review of Industrial Organization, 47 (3), November, 259-72.

Ellison, Glenn (2006), "Bounded Rationality in Industrial Organization", Econometric Society Monographs and the National Bureau of Economic Research, January.

Epley, Nicholas and Thomas Gilovich (2016), "The Mechanics of Motivated Reasoning", Journal of Economic Perspectives, 30 (3), Summer, 133-40.

Fehr, Ernst and Jean-Robert Tyran (2005), "Individual Irrationality and Aggregate Outcomes", Journal of Economic Perspectives, 19 (4), Fall, 43-66.

Friedman, Milton (1971 [1953]), "The Methodology of Positive Economics", in William Breit and Harold M. Hochman, editors, Readings in Microeconomics, New York: Holt, Rinehart and Winston, 23-47.

Greer, Douglas F. (1980), Industrial Organization and Public Policy, New York: Macmillan Publishing.

Grubb, Michael D. (2009), "Selling to Overconfident Consumers", American Economic Review, 99 (5), December, 1770-807.

Grubb, Michael D. (2015a), "Behavioral Consumers in Industrial Organization: An Overview", Review of Industrial Organization, 47 (3), November, 247-58.

Grubb, Michael D. (2015b), "Failing to Choose the Best Price: Theory, Evidence, and Policy", Review of Industrial Organization, 47 (3), November, 303-40.

Grubb, Michael D. and Victor J. Tremblay (2015), "Introduction: Behavioral Industrial Organization", Review of Industrial Organization, 47 (3), November, 243-5.

Gubler, Zachary (2014), "Reconsidering the Institutional Design of Federal Securities Regulation", William \& Mary Law Review, 56 (2), 409-65.

Gul, Faruk and Wolfgang Pesendorfer (2008), "The Case for Mindless Economics", in Andrew Caplin and Andrew Schotter, editors, The Foundations of Positive and Normative Economics: A Handbook, Princeton: Princeton University Press, 3-42.

Hall, R.L. and Charles J. Hitch (1939), "Price Theory and Business Behavior", Oxford Economic Papers, 2, May, 12-45.

Harstad, Ronald M. and Reinhard Selten (2013), "Bounded-Rationality Models: Tasks to Become Intellectually Competitive", Journal of Economic Literature, 51 (2), June, 496-511.

Heidhues, Paul and Botond Köszegi (2015), "On the Welfare Costs of Naiveté in the US Credit-Card Market”, Review of Industrial Organization, 47 (3), November, 341-54.

Kahneman, Daniel (2003), "Maps of Bounded Rationality: Psychology for Behavioral Economics", American Economic Review, 93 (5), December, 1449-75.

Kunda, Ziva (1990), “The Case of Motivated Reasoning”, Psychology Bulletin, 108 (3), November, 480-98.

Malmendier, Ulrike and Geoffrey Tate (2008), "Who Makes Acquisitions? CEO Overconfidence and the Market's Reaction", Journal of Financial Economics, 89 (1), July, $20-43$.

Malmendier, Ulrike and Geoffrey Tate (2011), "Overconfidence and Early-Life Experiences: The Impact of Managerial Traits on Corporate Finance Policies", Journal of Finance, 66 (5), October, 1687-733.

Martin, Stephen (2010), Industrial Organization in Context, New York: Oxford University Press. 
Oser, Jacob and William C. Blanchfield (1975), The Evolution of Economic Thought, New York: Harcourt Brace Jovanovich.

Pigou, A.C. and D.H. Robertson (1924), "Those Empty Boxes", Economic Journal, 34 (133), 16-31.

Rabin, Matthew (2013), "Incorporating Limited Rationality into Economics", Journal of Economic Literature, 51 (2), June, 528-43.

Russell, Thomas and Richard Thaler (1985), "The Relevance of Quasi Rationality in Competitive Markets", American Economic Review, 75 (5), December, 1071, 1082.

Samuelson, Larry (1997), Evolutionary Games and Equilibrium Selection, Cambridge: MIT Press.

Scherer, F.M. (1970), Industrial Market Structure and Economic Performance, Chicago: Rand McNally.

Simon, Herbert A. (1955), "A Behavioral Model of Rational Choice”, Quarterly Journal of Economics, 69 (1), February, 99-118.

Smith, Adam (1981 [1759]), The Theory of Moral Sentiments, Indianapolis: Liberty Fund.

Smith, Vernon (1991), "Rational Choice: The Contrast between Economics and Psychology", Journal of Political Economy, 99 (4), August, 877-97.

Spiegler, Ran (2011), Bounded Rationality and Industrial Organization, Oxford: Oxford University Press.

Stahl, Dale O. (2014), "Boundedly-Rational vs. Optimization-Based Behavior: A Distinction without a Difference", January, available at SSRN, https://ssrn.com/abstract= 2386851.

Stigler, George J. (1968), "Monopolistic Competition in Retrospect", in The Organization of Industry, Chicago: University of Chicago Press.

Stigler, George J. (1971), "The Theory of Economic Regulation", Bell Journal of Economics, 2 (1), Spring, 3-21.

Thaler, Richard (2000), "From Homo Economicus to Homo Sapiens", Journal of Economic Perspectives, 14 (1), Winter, 133-41.

Thaler, Richard H. (2016), "Behavioral Economics: Past, Present and Future", National Bureau of Economic Research, 27 May.

Tirole, Jean (1988), The Theory of Industrial Organization, Cambridge: MIT Press.

Tremblay, Victor J. and Carol Horton Tremblay (2012), New Perspectives on Industrial Organization: With Contributions from Behavioral Economics and Game Theory, New York: Springer.

Viscusi, W. Kip, Joseph E. Harrington, Jr and John M. Vernon (2005), Economics of Regulation and Antitrust, Cambridge: MIT Press.

Waldman, Don E. and Elizabeth Jensen (2016), Industrial Organization: Theory and Policy, Abingdon: Routledge. 
Elizabeth Schroeder, Carol Horton Tremblay, and Victor J. Tremblay - 9781784718985 Downloaded from PubFactory at 04/26/2023 09:16:15AM via free access 